\title{
. SHARING COMPUTATIONAL SKILLS TO ADDRESS NEGLECTED DISEASES IN LATIN AMERICA
}

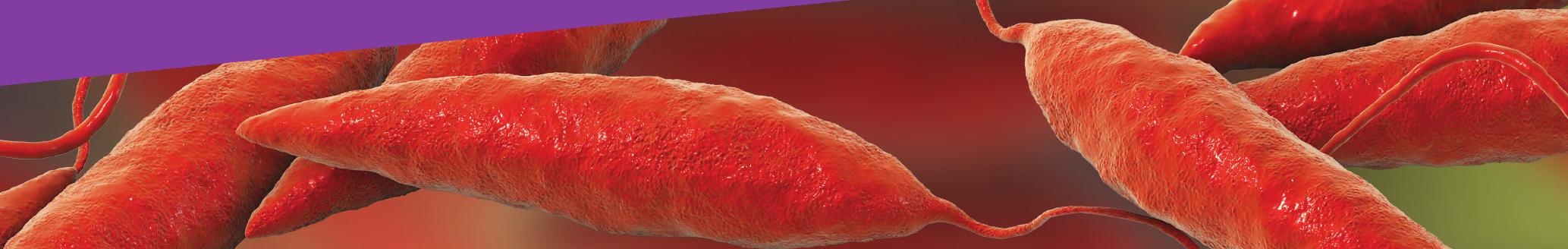

TROPICAL DISEASES ARE A SIGNIFICANT SOURCE OF DEATHS ACROSS LATIN AMERICA, BUT, UNTIL RECENTLY, THERE HAS BEEN LITTLE INTEREST IN DEVELOPING DRUGS AND VACCINES TO TACKLE THEM. AS PART OF THE INNOVATIVE CABANA PROJECT, DR RODRIGO OCHOA FROM THE UNIVERSITY OF ANTIOQUIA, IN COLOMBIA, USES HIS SKILLS IN BIOCHEMISTRY AND BIOINFORMATICS TO DISCOVER NEW DRUGS AND IMPROVE THE STATUS OF BIOCHEMICAL RESEARCH IN LATIN AMERICA

\section{TALK LIKE A}

\section{CHEMICAL SCIENTIST}

BIOINFORMATICS - using computational tools to understand large amounts of biological data

NEGLECTED TROPICAL DISEASES a group of around 20 diseases which affect large numbers of people in tropical regions of the world, but which have received little attention in terms of treatment and prevention

LEISHMANIASIS - an infection caused by the Leishmania parasite

PEPTIDES - short chains of amino acids, which are the molecular building blocks of proteins

RECEPTOR PROMISCUITY - a feature of some proteins that enables them to bind to lots of different molecules
The World Health Organization estimates that over 1.7 billion people, mainly in developing countries, are at risk of neglected tropical diseases (NTDs). NTDs, such as leishmaniasis and leprosy, cause over 200,000 deaths and millions of disabilities each year. Despite this, treatments either do not exist for many NTDs, or are too expensive to be deployed on a large scale. These diseases are neglected because they are not profitable for pharmaceutical companies to invest in, and the people whom they affect tend to be the poorest and most vulnerable in society, who have the least political voice. Additionally, developing countries, which these diseases primarily affect, often lack the capacity to carry out their own research to find new treatments and vaccines.

\section{CABANA (Capacity building for} bioinformatics in Latin America) is an international research project funded by the UK's Official Development Assistance Budget. Focusing on infectious diseases, as well as biodiversity and food security, CABANA supports scientists in Latin America to use bioinformatics methods to solve societal problems. Building these capabilities is crucial to enable Latin American countries to conduct research to find new treatments and vaccines for NTDs. CABANA is a collaboration between the European Bioinformatics Institute (EMBL-EBI) in the UK, and nine universities and research organisations spread across Latin America. As Dr Rodrigo Ochoa explains, the aim of CABANA is to, "provide connections with top research labs in Europe and Latin America, improving the competitiveness of the trainees and their research centres."

As part of his $\mathrm{PhD}$ in Chemical Sciences at the University of Antioquia, Colombia, Rodrigo participated in a six-month placement at EMBL-EBI, where he used structural bioinformatics and biophysics simulations to design peptides that can be used as potential vaccines for NTDs.

WHAT ARE PEPTIDES AND WHY ARE THEY IMPORTANT TO STUDY?

Peptides are short chains of amino acids that make up proteins. Proteins are the molecules that carry out most of the biological functions within our cells. Most drugs work by altering the ability of specific proteins to bind to other molecules and carry out their biological functions. Rodrigo studies the way in which proteins bind to each other. This process of 



\section{(5) \\ ABOUT CHEMICAL SCIENCES}

Chemical sciences is a broad field encompassing many aspects of chemical research. One of the largest areas of research is biochemistry, which is the study of the chemistry within living organisms. The behaviour and health of organisms is, ultimately, controlled by the chemical processes that occur inside and outside the cells, so biochemistry is crucial to understanding disease and finding new treatments and vaccines. There are both lab-based and computational ways of studying biochemistry, and the two complement each other very well. Modern-day biochemistry requires many more computational skills than it has in the past, and the area of bioinformatics is likely to keep growing.

\section{WHAT DOES MODERN}

\section{BIOCHEMISTRY LOOK LIKE?}

The core of biochemistry is analysing the chemical composition of the molecules that make up cells and conducting experiments to see how cells are affected by changing their composition, such as by applying drugs to try to correct disease.

Modern biochemistry has been driven by major advances in technology over the past 50 years, which allow us to measure and control the molecules within cells with ever increasing degrees of accuracy. Another major technological advance is the application of computing power to process very large amounts of data and look for patterns that could never be found by human researchers. This is the field of bioinformatics, which is a combination of computer science, statistics and biochemistry, and is one of the fastest growing fields within the life sciences. Computing power has also been used to conduct experiments that would be far too technically challenging, or time consuming, to conduct in the lab. Researchers can model complex molecules such as proteins on a computer and see what effect the millions of possible chemical variations have on their structure and function. They can then use this information to identify candidate molecules, which could be tested as drugs to target these proteins.

\section{AN EXCITING AND RAPIDLY}

\section{CHANGING FIELD}

Advances in computer power are constantly changing the limits of what is possible in bioinformatics and biochemistry. New projects such as AlphaFold, an artificial intelligence programme, take advantage of the latest techniques in computer science to search for solutions to longstanding biochemical questions. There is a real need to take these techniques from the established labs where they were developed, and apply them to problems affecting the developing world, where resources are much less available. This provides many opportunities for researchers at all stages of their careers, including their first steps on the career ladder, to make a difference to international problems that are currently neglected.

\section{EXPLORE A CAREER IN CHEMICAL SCIENCES}

- The Royal Society of Chemistry has an excellent careers section on its website. Find out more about what a career as a chemical scientist could offer you: edu.rsc.org/future-in-chemistry/career-options

- The CABANA project has several online courses teaching students about various aspects of bioinformatics: www.cabana.online

- Explore the work of The European Bioinformatics Institute (EMBL-EBI): www.ebi.ac.uk

- According to Payscale.com, the average salary for a bioinformatics scientist in the UK is £40,000: www.payscale.com/research/UK/Job=Bioinformatics_Scientist/Salary

- According to Erieri.com, the average salary for a bioinformatics scientist in Colombia is COP 50,000,000: www.erieri.com/salary/job/bioinformatics-scientist/colombia/bogota

\section{PATHWAY FROM SCHOOL TO CHEMICAL SCIENTIST}

- Chemistry and biology are the core subjects that are important to study at school.

- At university, biochemistry and molecular biology provide the basic knowledge that is needed to understand the types of problems Rodrigo is working on.

- Some form of training in statistics and programming is very valuable as computational methods are heavily used in most areas of bioinformatics and chemical sciences today. 
